Mongolian Geoscientist

Original article

\title{
A Carcharodontosaurid tooth from the Hasandong Formation (Lower Cretaceous) of South Korea
}

\author{
${ }^{1}$ Vertebrate Paleontological Institute of Incheon, Incheon 21974, Republic of Korea \\ ${ }^{2}$ Biological Sciences, Inha University, Incheon 22212, Republic of Korea \\ *Corresponding author: changyu1015@naver.com
}

Chan-gyu Yun ${ }^{1,2 *}$

\section{ARTICLE INFO}

Article history:

Received 04 April, 2020

Accepted 12 May, 2020

\begin{abstract}
A large tooth of theropod dinosaur that was recovered from the Hasandong Formation (Lower Cretaceous; Aptian-Albian) in Daedo island, Hadong Couty, South Gyeongsang Province of South Korea is redescribed. Although the tooth was misidentified as a "Prodeinodon"-like megalosaurid theropod at the first time, detailed comparisons with known theropod dentition anatomy strongly indicate that this tooth belongs to an Acrocanthosaurus-like basal carcharodontosaurid theropod. This referral is supported by its combination of large size, ovoid-shaped cervix outline, mesial carina that does not reach the cervix, labially displaced distal carina and large number of denticles. This tooth is different from other carcharodontosaurid teeth from the same formation in several anatomical aspects (e.g., smaller overall size, presence of transverse lines adjacent to the distal carina, presence of interdenticular sulci in distal carina, denticle densities, crown basal ratio), indicating that carcharodontosaurid diversity in the Early Cretaceous of Korea could have been higher, although these differences may represent positional or individual variations. The presence of Acrocanthosaurus-like theropod teeth (e.g., "Prodeinodon", "Wakinosaurus") from early Cretaceous deposits (Valanginian-Cenomanian) of South Korea, Japan, Mongolia and China indicates that North American Acrocanthosaurus atokensis possibly represents a form that immigrated from the Asia.
\end{abstract}

Keywords: Theropoda, Carcharodontosauridae, Daedo Island, Hadong County

\section{INTRODUCTION}

Isolated theropod teeth comprise an important role in understanding paleoenvironment, paleoecology, paleodiversity and anatomical information on various theropod clades in Mesozoic terrestrial ecosystems as they represent one of the most common fossils in terrestrial Mesozoic formations (e.g., Hendrickx et al., 2019). The abundance of theropod teeth in the fossil record is mainly due to the facts that theropod dinosaurs were polyphyodont animals, and their teeth covered with enamel represent one of the hardest skeletal elements in the whole skeleton (e.g., Hendrickx et al., 2019). Thus, acceptable taxonomic identities of isolated theropod teeth could be very important in

(C) The Author(s). 2020 Open access This article is distributed under the terms of the Creative Commons Attribution 4.0 International License (https://creativecommons.org/licenses/by/4.0/), which permits unrestricted use, distribution, and reproduction in any medium, provided you give appropriate credit to the original author(s) and source, provide a link to the Creative Commons license, and indicate if changes were made. 
dinosaur biogeography and evolution, especially for the sediments that lack articulated skeletons or isolated, well preserved bony elements.

Despite the abundance of ichnofossils such as eggs or footprints, most dinosaur body fossils that have been reported from the Korean Peninsula represent isolated, incomplete or fragmentary materials that are not yet widely reported to the international paleontological community (Lee, 2003; Choi and Lee, 2017). Among these fossils, isolated theropod teeth are currently only reported from the Hasandong Formation (Aptian-Albian) that is distributed in the southeastern part of the Korean Peninsula (Choi and Lee, 2017), and previous taxonomic identifications on most of these fossils were made through preliminary descriptions at the times when phylogenetically informative variations in theropod teeth were poorly described. Nevertheless, they represent important record for understanding theropod diversity and evolution during the early Cretaceous of the Northeastern Asia.

In 2002, Lim et al. (2002) reported a large theropod tooth (KS 7001) from the Hasandong Formation that is exposed in the Daedo island, Hadong County of South Gyeongsang Province, and they assigned the tooth as Megalosauridae (Fig. 1). The key features that Lim et al. (2002) identified the tooth as a megalosaurid is the strongly laterally compressed morphology of the crown, and its similarities with "Prodeinodon" teeth from China and Mongolia that had been considered as megalosaurids. Later, Yun et al. (2007) redescribed KS 7001 briefly, and they followed the classification made by Lim et al. (2002) that KS 7001 is a megalosaurid. However, it is now known that laterally compressed crown morphology is not unique for the megalosaurid teeth (Hendrickx et al., 2015a), and the identifications of "Prodeinodon" teeth as megalosaurid theropods are highly doubtful (e.g., Averianov and Skutschas, 2009). Based on these factors, some authors have referred KS 7001 as an Indeterminate Theropoda with unavailable further taxonomic resolution (Carrano et al., 2012; Choi and Lee, 2017). However, it has been recently shown that although most theropod teeth may not be diagnositic to the species level, they possess several important anatomical characters that can be used for assigning them to at least several certain taxonomic levels (e.g., family-level clade; Hendrickx et al., 2019). Here, the author redescribes KS 7001 to correctly identify its taxonomic identity, and discusses about its implications on dinosaur biogeography and evolution.

Institutional Abbreviations - AMNH, American Museum of Natural History; IVPP, Institute of Vertebrate Paleontology and Paleoanthropology; KIGAM VP, Korea Institute of Geoscience and Mineral Resources; KS, Kyeongnam Science High School Museum.

Anatomical Abbreviations - AL, apical length;
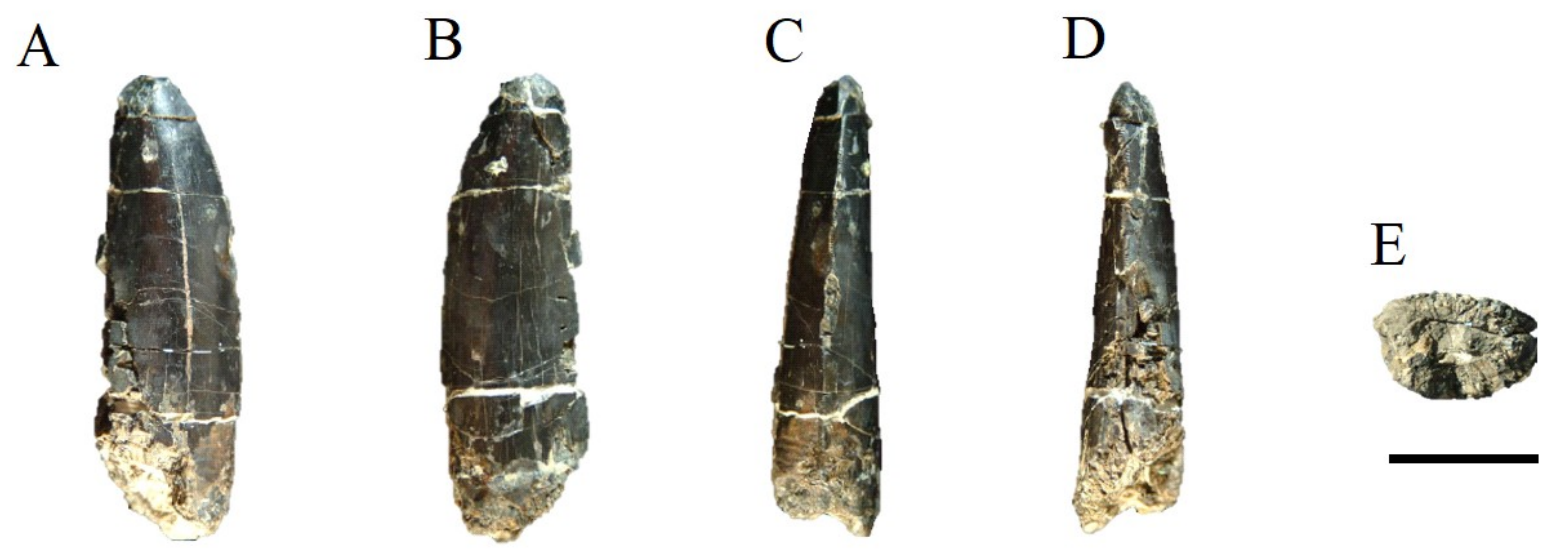

Fig. 1. Remaining photographs of KS 7001, modified from Yun et al. (2007). Large theropod tooth in lingual (A), labial (B), mesial (C), distal (D), and distal (E), and basal (E) views. Scale bar = $20 \mathrm{~mm}$. 
CA, crown andgle; CBL, crown base length; $\mathrm{CBR}$, crown base ratio; $\mathrm{CBW}$, crown base width; $\mathrm{CH}$, crown height; $\mathrm{CHR}$, crown height ratio; CWR, crown width ratio; DA, distoapical denticle density; DAVG, average distal denticle density; DC, distocentral denticle density; DSDI, ; MA, mesioapical denticle density; MAVG, average mesial denticle density; MB, mesiobasal denticle density; MC, mesiocentral denticle density; MCL, mid-crown length; MCW, mid-crown width; MDDD, minimum distal denticle density; MMDD, minimum mesial denticle density.

\section{GEOLOGICAL BACKGROUND}

The Hasandong Formation is the middle unit of the Sindong Group which is approximately 1200 thick on average, and it is the lowermost group of the Gyeongsang Supergroup (Lee, 2008). The formation is composed of alluvial and fluvial sediments, and shows alternating channel and interchannel sediments (Lee, 2008). The rocks comprising Hasandong Formation include reddish and grey sandstone, reddish to greenish grey sandy mudstone, and dark grey shale (Lee, 2008). SHRIMP and LA-MCICPMS U-Pb analyses provide an age between $118.0 \pm 2.6 \mathrm{Ma}$ (Upper Aptian) for the Hasandong Formation (Lee et al., 2018), and molluscan faunas indicate the age about Aptian to Albian (Yang, 1982).

Numerous vertebrate fossils have been reported from the formation, including fish, turtles, pterosaurs, and dinosaurs (Choi and Lee, 2017).

\section{MATERIALS AND METHODS}

Unfortunately, the original fossil of KS 7001 is currently lost (C.S. Yun, pers. comm. 2020). Therefore, a remaining high-quality cast made of gypsum is mainly studied (Fig. 2). The original descriptions made by Lim et al. (2002) and Yun et al. (2007) are partly referenced for the parts (e.g., portions of distal carina) that cannot be observed in the cast.

The anatomical nomenclature on the theropod teeth made by Hendrickx et al. (2015b) and Soto et al. (2020) is used. For the comparisons with other known theropod teeth, datasets of Hendrickx et al. (2015a, 2019) and Soto et al. (2020) is mainly referenced. Comparisons with other known Northeastern Asian theropod teeth were made through an extensive review on the literature.

\section{SYSTEMATIC PALEONTOLOGY}

\author{
Allosauroidea Marsh, 1878 \\ Carcharodontosauridae Stromer, 1931 \\ Carcharodontosauridae indet.
}

\section{TAXONOMIC REFERRAL}

KS 7001 is identified as a mesial tooth of basal carcharodontosaurid theropod, based on the combination of large size, large number of denticles, ovoid outline of base, nearly straight distal margin, mesial carina that does not reaches the cervix, and distal carina that is strongly displaced labially (Hendrickx et al., 2015a, 2019; Soto et al., 2020).

KS 7001 is a large theropod tooth crown, as its preserved height is over $60 \mathrm{~mm}$. Although size must be treated with caution when identifying theropod tooth as this feature varies allometrically (Hendrickx et al., 2019), this feature has been demonstrated to be useful to differentiate the teeth of various theropod taxa (Hendrickx and Mateus, 2014; Hendrickx et al., 2019). According to Hendrickx et al. (2019), tooth crowns of more than $60 \mathrm{~mm}$ occur only in Allosauroidea (Allosaurus, Sinraptor, carcharodontosaurids including Acrocanthosaurus, Carcharodontosaurus, Mapusaurus, Giganotosaurus), Ceratosaurus, large megalosaurids (Afrovenator, Megalosaurus, Torvosaurus), spinosaurids, and derived tyrannosauroids. KS 7001 can be easily differentiated from spinosaurids by its lack of coniodont condition, absence of fluted external surface, and much larger denticle sizes (e.g., Hendrickx et al., 2019; Yun, 2019). KS 7001 differs from Ceratosaurus by its much elongate morphology (higher CHR) and lack of flutes in the lingual surface (Hendrickx et al., 2015a, 2019; Yun, 2019). KS 7001 differs from Allosaurus in lacking pachydont condition $(\mathrm{CBR}<0.75)$, presence of mesial denticles that are larger than distal ones, lack of lingually positioned longitudinal groove adjacent to the mesial carina, and absence of mesial carina spiraling mesiolingually (Hendrickx et al., 


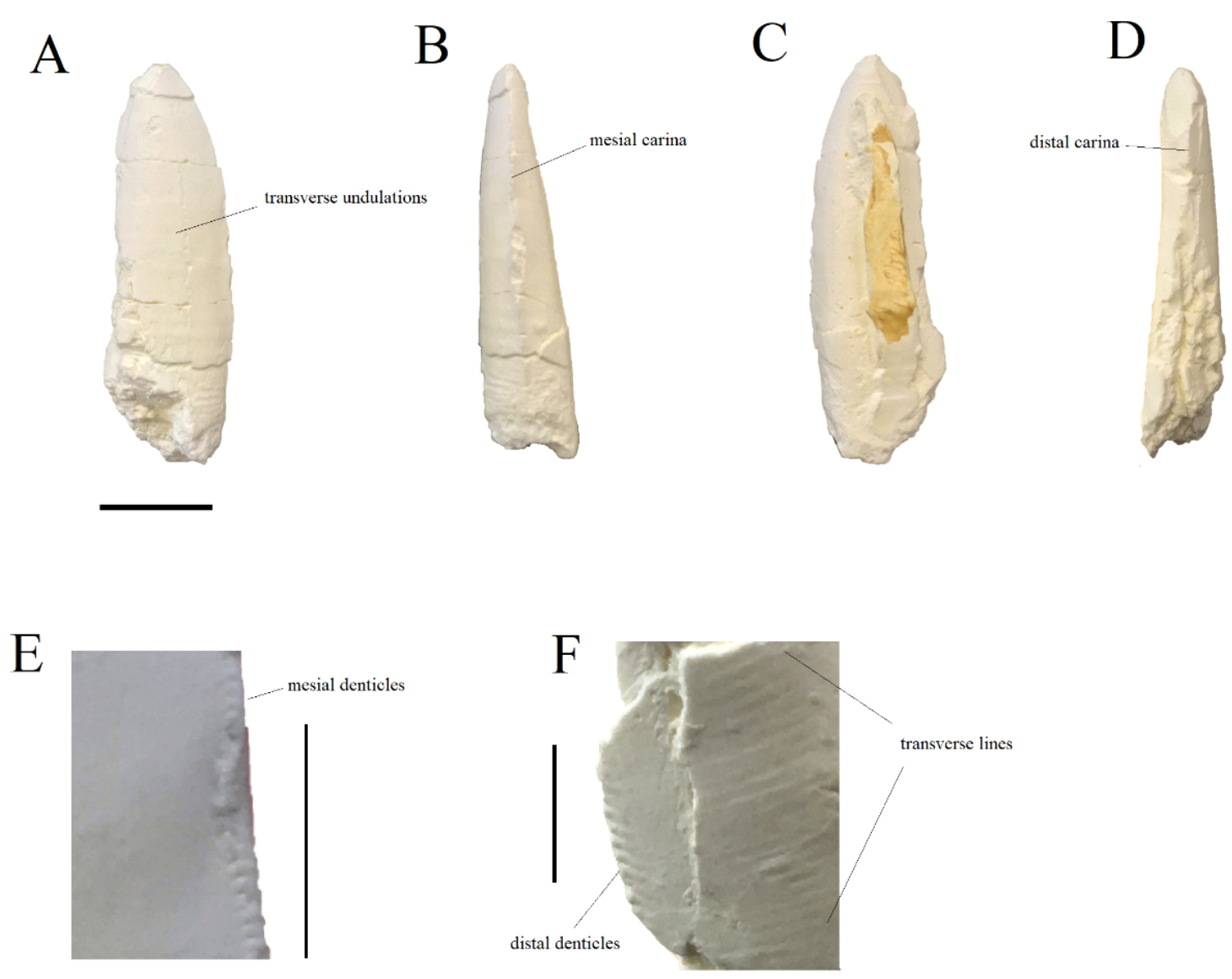

Fig. 2. Cast of KS 7001 in lingual (A), mesial (B), labial (C), distal (D) views, and magnified mesial (E) and distal (E) carinae. Scale bar $=20 \mathrm{~mm}(\mathrm{~A}-\mathrm{D}),=5 \mathrm{~mm}(\mathrm{E}, \mathrm{F})$

2015a, 2019). KS 7001 can be differentiated from Sinraptor in having mesiolingually twisting mesial carina, absence of mesiodistally concave surfaces adjacent to the carinae on the lingual surface, and having more elongated morphology (Hendrickx et al., 2019, 2020). Teeth of derived tyrannosauroids highly differ from KS 7001 by their pachydont condition $(\mathrm{CBR}>0.75)$ and lingually twisted mesial carina (Hendrickx et al., 2019). As these comparisons are based on key apomorphic features of each comparative taxon, it is highly unlikely that KS 7001 belongs to one of these clades of theropods.

The overall morphology and details of KS 7001 are highly reminiscent mesial teeth of carcharodontosaurids and large megalosaurids. Mesial teeth of megalosaurids are quite similar to those of carcharodontosaurids (Hendrickx et al., 2015a) and as Lim et al. (2002) assigned KS 7001 to a megalosaurid, comparisons with megalosaurid and carcharodontosaurid dentition are especially important. In mesial teeth of megalosaurids, the base is lanceolate-shaped (Hendrickx et al., 2015a) whereas in KS 7001, the outline at the cervix is ovoid-shaped, which is one of the unambiguous dental synapomorphies of carcharodontosaurids (Hendrickx et al., 2019). Furthermore, the distal carina of mesial megalosaurid teeth is centrally positioned to weakly offset labially, making both carinae are aligned on the same plane (Hendrickx et al., 2015a). In contrast, distal carina of KS 7001 is strongly displaced labially, which is a key difference between mesial teeth of megalosaurids and carcharodontosaurids (Hendrickx et al., 2015a). In summary, KS 7001 can be confidently assigned to Carcharodontosauridae.

As KS 7001 is an isolated tooth, identifying its exact systematic position within Carcharodontosauridae is difficult. Several 
morphologies on the tooth, however, suggest against it being a carcharodontosaurine. In carcharodontosaurines

Carcharodontosaurus,

(e.g.

Mapusaurus), the mesial carina extends on the entire crown height (Hendrickx et al. 2019) whereas in KS 7001, the mesial carina does not reach the cervix like most mesial teeth of Acrocanthosaurus. Furthermore, the distal margin of KS 7001 is nearly straight like basal carcharodontosaurid Acrocanthosaurus, but the distal profile is sigmoid with the basal half slightly concave and the apical half weakly convex in carcharodontosaurines (Hendrickx et al. 2019). Lastly, KS 7001 shares a large number of denticles (more than $12 / 5 \mathrm{~mm}$ ) on the carinae with Acrocanthosaurus within Carcharodontosauridae (Hendrickx et al., 2019; Soto et al., 2020), whereas in carcharodontosaurines, denticles are much larger, as they generally possess denticle densities less than 10 per $5 \mathrm{~mm}$ on the carinae (Hendrickx et al., 2015a). Thus, KS 7001 is referable to a basal carcharodontosaurid that is similar to Acrocanthosaurus.

\section{DESCRIPTION}

KS 7001 is a large theropod tooth lacking the small portion of the apex (Fig. 2). Although the mesial carina is well preserved, only small portions of the distal carina are preserved. As it lacks the root and the combination of relatively straight distal margin as well as labiolingually thick morphology suggest KS 7001 represents a tooth fell out from the mesial part of the skull during life (Hendrickx and Mateus 2014). Based on overall morphology, it is probable that $\mathrm{KS}$ 7001 is from either a right side of the upper jaw or left side of the lower jaw.

The tooth is particularly large, as the preserved $\mathrm{CH}$ is $62 \mathrm{~mm}$. If complete, it would have been about $67 \mathrm{~mm}$. The base is relatively narrow mesiodistally (CBL of $20 \mathrm{~mm}$ ) and wide labiolingually (CBW of $13 \mathrm{~mm}$ ) so that the base of the crown is ovoid-shaped (CBR of 0.65). The CWR is 4.77 and estimated actual CWR is 5.15, assuming the missing apex was about 5 $\mathrm{mm}$. The CHR in preserved status is 3.1 , and 3.35 for a complete tooth. In lateral view, the apical half of the mesial margin is distally curved, while the basal half is nearly straight. The distal margin is nearly straight. Welldeveloped transverse undulations are present along most of the crown length. Interestingly, closely spaced transverse lines are present on the apical third of the crown just mesial to the distal carina (Fig. 2F), and it is likely that these are not growth lines (Lim et al. 2002). The external texture is smooth. The MCL is $15 \mathrm{~mm}$ and MCW is $11 \mathrm{~mm}$, thus the cross section at the midheight is lenticular shaped. The estimated AL is about $65 \mathrm{~mm}$, and estimated CA is about $78^{\circ}$. In mesial view, the mesial carina is welldeveloped but it does not reach the cervix, and it is centrally positioned. Denticle densities are about $2.9 / \mathrm{mm}$ at the apex (MA), $2.4 / \mathrm{mm}$ at the midheight (MC), and $2.4 / \mathrm{mm}$ at the base (MB) as partly noted by Lim et al. (2002). Thus, the MAVG is $2.56 / \mathrm{mm}$ and MMDD is $2.4 / \mathrm{mm}$. In distal view, the carina is strongly displaced labially. Although the carina is only partly preserved, it is nearly straight. Denticles in distal carina tend to be mesiodistally longer than the mesial denticles, and their mesiodistal axes are slightly inclined basally (Fig. 2E, F). Short interdenticular sulci present between the distal denticles and they extend onto the crown, but these are totally absent in the mesial carina. Denticle densities are about $3.4 / \mathrm{mm}$ at the apex (DA) and $2.4 / \mathrm{mm}$ at the midheight (DC) (Lim et al. 2002). Thus, the DAVG is $2.9 / \mathrm{mm}$ and MDDD is $2.4 / \mathrm{mm}$. This results DSDI ratios about 0.88 and 1, after Smith et al. (2005) and Soto et al. (2020).

\section{DISCUSSION \\ Comparisons with Korean theropod teeth -} Body fossils of theropod dinosaurs are very poorly documented from the terrestrial Mesozoic formations in South Korea, and only fragmentary remains such as a rib, femur, and isolated teeth have been reported (e.g., Choi and Lee, 2017). Among these, theropod teeth are currently only recovered from the Hasandong Formation, including the teeth of cf. Acrocanthosaurus sp., premaxillary tooth of a small tyrannosauroid, and additional fragmentary teeth with uncertain phylogenetic positions (Lee, 2007, 2008; Choi and Lee, 2017). Thus, identification of KS 7001 as a 
carcharodontosaurid is significant, as it opens the possibility of detailed taxonomic assignments on many more of these materials.

Among these, one comparison is particularly important. Lee (2007) described three large theropod teeth (KIGAM VP 200501-03) from the Hasandong Formation and referred them as cf. Acrocanthosaurus sp., based on a combination of large size, mesial carina that does not reaches the cervix, and denticle densities. As KS 7001 also shows several similarities with Acrocanthosaurus teeth, the possibility of KS 7001 and KIGAM VP 20050103 representing the same taxon is considered further. Among the teeth described by Lee (2007), KIGAM VP 200501 represents the most well-preserved material as it only lacks the apical portion (Fig. 3). Denticles in KIGAM VP 200501 tend to be larger than those in KS 7001, as its denticle densities are $2 / \mathrm{mm}$ in $\mathrm{MC}, 1.8 /$ $\mathrm{mm}$ in DA and DC, and $2.8 / \mathrm{mm}$ in the DB (Lee, 2007). This suggests that distal denticles are generally larger than mesial denticles in KIGAM VP 200501, whereas in KS 7001, an opposite condition is present. Additionally, mesiodistal axes of distal denticles in KS 7001 are slightly inclined basally, and transverse lines are present mesial to the distal carina. In KIGAM VP 200501, the axes are perpendicular to the distal carina and there are no transverse lines (Lee, 2007). Furthermore, interdenticular sulci in distal carina of KS 7001 are extending onto the crown, but such condition is absent in KIGAM VP 200501 (Lee, 2007). Lastly, KS 7001 represents a tooth that is labiolingually thicker than KIGAM VP 200501, as the CBR of the latter is only 0.51 (Lee, 2007). In summary, differences in detail suggest a possibility that KS 7001 represents a distinct taxon from the teeth described by Lee (2007). However, large degrees of differences in tooth morphology (e.g., denticle densities) within the same theropod taxon have been reported (e.g., Smith, 2005; Sereno and Brusatte, 2008), so it is equally possible that these differences merely represent individual or positional variation. So currently, the author thinks it is too soon to conclude that KS 7001 represents different taxon from

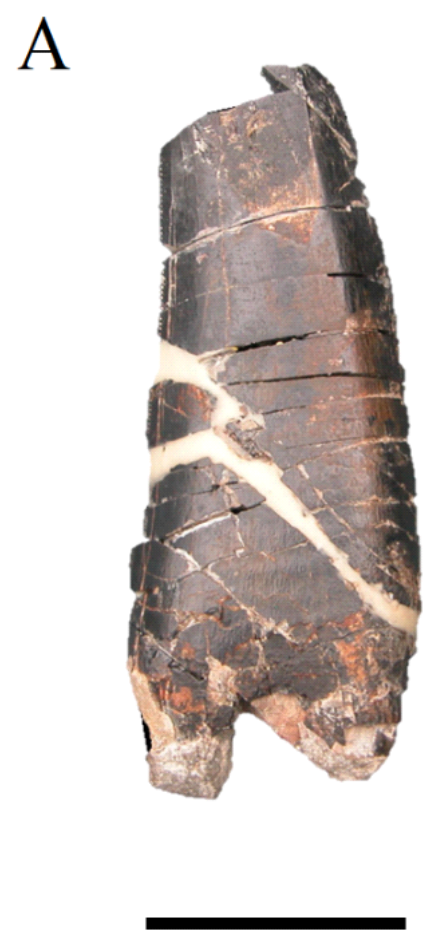

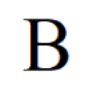
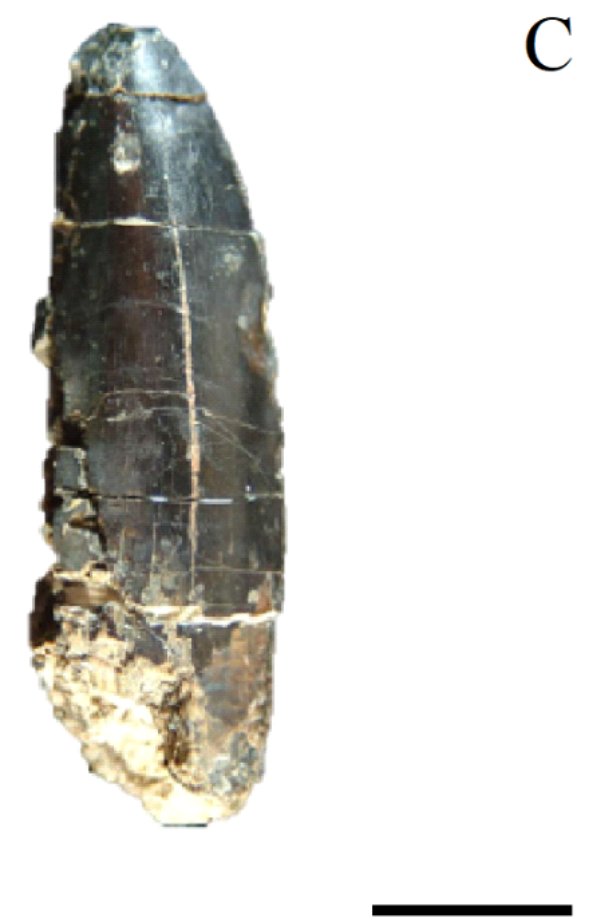

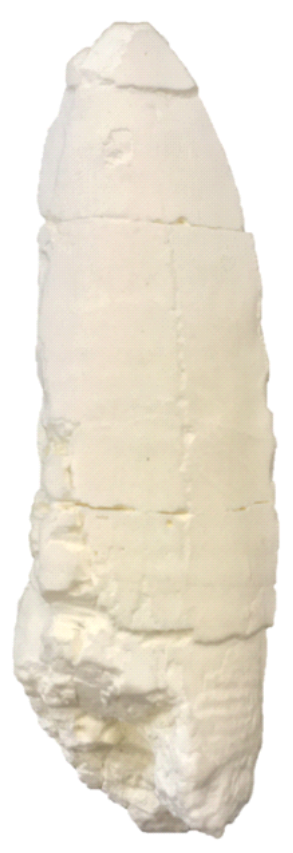

Fig. 3. Large theropod teeth that recovered from the Hasandong Formation. cf. Acrocanthosaurus sp. KIGAM VP 200501 (A), Carcharodontosauridae indet. KS 7001 (B), and cast of KS 7001 (C). A and B are modified from Lee (2007) and Yun et al. (2007). Scale bar $=30 \mathrm{~mm}(\mathrm{~A}),=20 \mathrm{~mm}(\mathrm{~B}, \mathrm{C})$. 
KIGAM VP 200501, albeit some differences are present between them.

\section{Implications on dinosaur evolution and biogeography - The recognition of KS 7001 as} an Acrocanthosaurus-like carcharodontosaurid bears several important implications on taxonomy of isolated theropod teeth from lower Cretaceous deposits of Northeastern Asia and evolution of Acrocanthosaurus. Historically, large theropod teeth have been collected from various lower Cretaceous formations from the Japan, China, Mongolia and South Korea that range from Valanginian to Cenomanian (Osborn, 1924; Hasegawa et al., 1992; Okazaki, 1992; Lim et al., 2002; Matsuoka et al., 2002; Weishampel et al., 2004; Lee, 2007; Mo et al., 2014) and they all exhibit similar morphologies with KS 7001 (e.g., Lim et al., 2002). Some of these teeth have received names like "Prodeinodon" or "Wakinosaurus", and considered as megalosaurids (Okazaki, 1992; Lim et al., 2002). The hypothesis of "Prodeinodon" teeth represent dromaeosaurid theropods (Averianov and Skutschas, 2009) is not supported, as "Prodeinodon" teeth (e.g., AMNH 6265, 6551, IVPP V4794) represent much larger teeth even more than those of largest dromaeosaurids, and they lack several key synapomorphies (e.g., 8-shaped cross section, distal denticles that are much larger than mesial ones) of Dromaeosauridae (Osborn, 1924; Mo et al., 2014; Hendrickx et al., 2019). Here, all of these teeth are regarded as Acrocanthosaurus-like theropods as they share several key characters with Acrocanthosaurus, including overall size and shape, nearly straight distal margin, ovoid basal part, mesial carina that does not reach the cervix, and large number of denticles (Hendrickx et al., 2015a, 2019). Of note, similarities with "Prodeinodon" teeth with carcharodontosaurids have been recognized several times (e.g., Lee, 2007; Mo et al., 2014).

The Cedar Mountain Formation in east-central Utah represents one of the best-preserved sequences of vertebrate faunal changes that occurred through the early Cretaceous of North America. The formation can be divided as three members that include distinct vertebrate faunas, including Yellow Cat Member (Barremian or older), Ruby Ranch Member (Aptian-Albian), and Mussentuchit Member (AlbianCenomanian) (Kirkland et al., 1999). Fossils of Acrocanthosaurus are only present in Ruby Ranch Member within the formation (Kirkland et al., 1999), indicating Acrocanthosaurus was absent from North America before the Aptian.

The abundance of Acrocanthosaurus-like teeth in lower Cretaceous deposits (ValanginianCenomanian) of Northeastern Asia with records that are significantly older than Aptian, suggests that North American Acrocanthosaurus atokensis may represent a form that immigrated from the Asia during the Aptian or slightly before. Similar faunal immigrations from Asia to North America during Aptian-Albian times have been reported in many vertebrates including other dinosaurs (e.g., Russell, 1993; Farke et al., 2014). This hypothesis may explain why Acrocanthosaurus was the single largebodied carcharodontosaurid theropod during the Aptian-Albian times of North America (D'Emic et al., 2012). If true, the arrival of Acrocanthosaurus or its direct ancestor into the North America would have been a devastating event for the endemic large carnivorous theropods (e.g., Utahraptor) in North America, in which they were all replaced by Acrocanthosaurus (Kirkland et al., 1999). However, as this hypothesis is largely based on records of isolated teeth, it should be considered as tentative.

\section{ACKNOWLEDGEMENTS}

The author thanks Dr. Cheol-Soo Yun for kindly loaning a cast of KS 7001. The author also thanks Dr. Jong-Deock Lim and his colleagues for discovering and studying the original fossil of KS 7001, which was a great contribution on Korean vertebrate paleontology. Discussions with Christophe Hendrickx about dental anatomy of theropods were also very helpful. Lastly, the author thanks Haeun Lee and Sujung Ji for their assistances on observing the cast of KS 7001. This manuscript was benefited by two anonymous reviewers.

\section{REFERENCES}

Averianov, A.O., Skutschas, P.P. 2009. Additions to the Early Cretaceous dinosaur 
fauna of Transbaikalia, eastern Russia. Proceedings of the Zoological Institute of the Russian Academy of Sciences, v. 313, p. 363378.

Carrano, M.T., Benson, R.B.J., Sampson, S.D. 2012. The phylogeny of Tetanurae (Dinosauria: Theropoda). Journal of Systematic Palaeontology, v, 10, p. 211-300. https:// doi.org/10.1080/14772019.2011.630927

Choi, S., Lee, Y.-N. 2017. A review of vertebrae body fossils from the Korean Peninsula and perspectives. Geosciences Journal, v. 21, p. 867-889. https:// doi.org/10.1007/s12303-017-0040-6

D'Emic, M.D., Melstrom, K.M., Eddy, D.R. 2012. Paleobiology and geographic range of the large-bodied Cretaceous theropod dinosaur Acrocanthosaurus atokensis. Palaeogeography, Palaeoclimatology, Palaeoecology, v. 333-334, p. 13-23. https:// doi.org/10.1016/j.palaeo.2012.03.003

Farke, A.A., Maxwell, W.D., Cifelli, R.L., Wedel, M.J. 2014. A Ceratopsian Dinosaur from the Lower Cretaceous of Western North America, and the Biogeography of Neoceratopsia. PLoS ONE, v. 9(12), e112055. $\quad$ https://doi.org/10.1371/ journal.pone.0112055

Hasegawa, Y., Murata, M., Wasada, K., Manabe M. 1992. The First Carnosaur (Saurischia; Theropoda) from Japan: a Tooth from the Cenomanian Mifune Group of Kyushu. Science Reports of the Yokohama National University, v. 2, p. 41-49.

Hendrickx, C., Mateus, O. 2014. Abelisauridae (Dinosauria: Theropoda) from the Late Jurassic of Portugal and dentition-based phylogeny as a contribution for the identification of isolated theropod teeth. Zootaxa, v. 3759, p. 1-74. https:// doi.org/10.11646/zootaxa.3759.1.1

Hendrickx, C., Mateus, O., Araújo, R. 2015a. The dentition of megalosaurid theropods. Acta Palaeontologica Polonica, v. 60(3), p. 627-642. https://doi.org/10.4202/ app.00056.2013

Hendrickx, C., Mateus, O., Araújo, R. 2015b. A proposed terminology of theropod teeth (Dinosauria: Saurischia). Journal of
Vertebrate Paleontology, v. 35(5), e982797. https:// doi.org/10.1080/02724634.2015.982797

Hendrickx, C., Mateus, O., Araújo, R., Choiniere, J. 2019. The distribution of dental features in non-avian theropod dinosaurs: Taxonomic potential, degree of homoplasy, and major evolutionary trends. Palaeontologia Electronica, v. 22(3), p. 1-110. https:// doi.org/10.26879/820

Hendrickx, C., Stiegler, J., Currie, P. J., Han, F., Xu, X., Choiniere, J., Wu, X.-C. 2020. Dental anatomy of the apex predator Sinraptor dongi (Theropoda: Allosauroidea) from the Late Jurassic of China. Canadian Journal of Earth Sciences. https://doi.org/10.1139/cjes-20190231

Kirkland, J.I., Cifelli, R.L., Britt, B.B., Burge, D.L., DeCourten, F.L., Eaton, J.G., Parrish, J.M. 1999. Distribution of vertebrate faunas in the Cedar Mountain Formation, east-central Utah. Miscellaneous Publication of Utah Geological Survey, v. 99, p. 201-217.

Lee, T.-H., Park, K.-H., Yi, K. 2018. Nature and evolution of the Cretaceous basins in the eastern margin of Eurasia: a case study of the Gyeongsang Basin, SE Korea. Journal of Asian Earth Sciences, v. 166, p. 19-31. https:// doi.org/10.1016/j.jseaes.2018.07.004

Lee, Y.-N. 2003. Dinosaur bones and eggs in South Korea. Memoir of the Fukui Prefectural Dinosaur Museum, v. 2, p. 113-121.

Lee, Y.-N. 2007. New theropod teeth from the Juji Island (Hasandong Formation), Daedo-ri, Hadong County, South Gyeongsang Province. Journal of the Geological Society of Korea, v. 43, p. 151-166.

Lee, Y.-N. 2008. The first tyrannosauroid tooth from Korea. Geosciences Journal, v. 12, 1924. https://doi.org/10.1007/s12303-008-0003-z

Lim J.-D., Martin, L.D., Baek, K.-S. 2002. The first megalosaurid tooth from South Korea. Current Science, v. 82, p. 326-328.

Marsh, O. 1878. Notice of new dinosaurian reptiles. American Journal of Science, v. 15, 241-244. https://doi.org/10.2475/ajs.s315.87 .241

Matsuoka, H., Kusuhashi, N., Takada, T., Setoguchi, T. 2002. A clue to the Neocomian vertebrate fauna: initial results from the Kuwa 
-jima "Kaseki-kabe" (Tetori Group) in Shiramine, Ishikawa, central Japan. Memoirs of the Faculty of Science, Kyoto University, Series of Geology and Mineralogy, v. 59, p. 33-45.

Mo, J., Huang, C., Xie, S., Buffetaut, E. 2014. A megatheropod tooth from the Early Cretaceous of Fusui, Guangxi, Southern China. Acta Geologica Sinica, v. 88, p. 6-12. https://doi.org/10.1111/1755-6724.12177

Okazaki, Y. 1992. A new genus and species of carnivorous dinosaur from the Lower Cretaceous Kwanmon Group, Northern Kyushu. Bulletin of the Kitakyushu Museum of Natural History, v. 11, p. 87-90.

Osborn, H.F. 1924. Sauropoda and Theropoda from the Lower Cretaceous of Mongolia. American Museum Novitates, v. 128, p. 1-7.

Russell, D.A. 1993. The role of Central Asia in dinosaurian biogeography. Canadian Journal of Earth Sciences, v. 30, p. 2002-2012. https://doi.org/10.1139/e93-176

Sereno, P.C., Brusatte, S.L. 2008. Basal abelisaurid and carcharodontosaurid theropods from the Lower Cretaceous Elrhaz Formation of Niger. Acta Palaeontogica Polonica, v. 53(1), p. 15-46. https:// doi.org/10.4202/app.2008.0102

Smith, J.B. 2005. Heterodonty in Tyrannosaurus rex: implications for the taxonomic and systematic utility of theropod dentitions. Journal of Vertebrate Paleontology, v. 25, p. 865-887. https://doi.org/10.1671/0272-4634 (2005)025[0865:HITRIF]2.0.CO;2

Smith, J.B., Vann, D.R., Dodson, P. 2005. Dental morphology and variation in theropod dinosaurs: Implications for the taxonomic identification of isolated teeth. The Anatomical Record Part A: Discoveries in Molecular, Cellular, and Evolutionary Biology, v. 285, p. 699-736. https:// doi.org/10.1002/ar.a.20206
Soto, M., Torino, P., Perea D. 2020. A large sized megalosaurid (Theropoda, Tetanurae) from the late Jurassic of Uruguay and Tanzania. Journal of South American Earth Sciences, v. 98, p. 102458. https:// doi.org/10.1016/j.jsames.2019.102458

Stromer, E. 1931. Wirbeltiere-Reste der Baharijestufe (unterestes Canoman). Ein Skelett-Rest von Carcharodontosaurus nov. gen. Abhandlungen der Bayerischen Akademie der Wissenschaften, Mathematisch -naturwissenschaftliche Abteilung, v. 9, p. 123.

Weishampel, D.B., Barrett, P.M., Coria, R.A., Loeuff, J.L., Xing, X., Xijin, Z., Sahni, A., Gomani, E.M.P., Noto, C.R. 2004. Dinosaur Distribution. in Weishampel, D.B., Dodson, P., Osmólska, H., eds., The Dinosauria, 2nd ed.: University of California Press, Berkeley, p. 517-606. https://doi.org/10.1525/ california/9780520242098.003.0027

Yang, S.Y. 1982. Geology around the typelocality of Trigonioides kodairai and age of the Nagdong Subgroup. Journal of the Geological Society of Korea, v. 18, p. 67-72.

Yun, C.S., Baek, K.S., Jeong, Y.H. 2007. Cretaceous reptilian teeth from the Gyeongsang Basin. Journal of the Paleontological Society of Korea, v. 23, p. 2747.

Yun, C-G. 2019. Comments on the ecology of Jurassic theropod dinosaur Ceratosaurus (Dinosauria: Theropoda) with critical reevaluation for supposed semiaquatic lifestyle. Volumina Jurassica, v. 17, p. 111116. 